\title{
Are Athletes Properly Hydrating: What do we Know?
}

\section{Janine Margarita R Dizon*}

Department of Rehabilitation, University of South Australia, Australia

Heat related injuries have been considered as one of the detrimental injuries in sports activities [1]. As such, research related to the assessment of hydration levels, coaches and athletes' knowledge of proper hydration in training and competition and development of hydration guidelines and strategies have flourished in the literature [2-5]. Given the vast amount of information to guide athletes in maintaining an optimum state of hydration to prevent heat related injuries, there is limited evidence regarding the utilization of information in actual and practical scenario.

Hydration recommendations and strategies have been developed and made available to guide coaches and athletes to maximize fluid replacement in order to prevent heat related injuries [5,6]. Several important factors were considered, amongst which are assessment of type of sporting activity, fluid levels, hydration opportunities, timing of fluid intake and ways to measure fluid loss. However, there is still limited knowledge on proper hydration amongst coaches and athletes $[2,4]$. Knowledge regarding ways to assess fluid levels, hydration status and fluid loss relevant to hydration knowledge are very limited. In some reports, there is evidence that athletes and coaches have some knowledge on proper hydration and fluid replacement. However, there is limited information regarding use of such strategies during training and competition [2,4]. Both cases highlight an important concern because without proper knowledge regarding hydration and fluid replacement, and without applying the proper knowledge in actual practice, it would not be possible to hydrate correctly and thus, dehydration and heat related injuries cannot be prevented.

\section{What Needs to be Done in Practice?}

Much work is needed to educate athletes and coaches on proper hydration strategies relevant to the needs of the sport. Hydration education programs based on existing guidelines consisting of essentials of hydration such as type of fluids to drink, amount of fluids to take, periods of hydration and opportunities for hydration during training and competition should be designed for coaches and athletes. More importantly, hydration programs need to be utilized by coaches and athletes and thus, strategies that improve adherence to proper hydration need to be identified. Hydration programs need to be practical and provide realistic opportunities to facilitate the use of proper hydration guidelines especially during competition and venues where dehydration is likely to occur.

In line with this, we at the Department of Sports Science, University of Santo Tomas, Manila, Philippines, have developed a hydration program for collegiate coaches and athletes to improve their knowledge on the essentials of proper hydration and practical measures to undertake in monitoring levels of hydration. Proper hydration is important in the Philippines due to the tropical and humid weather conditions. Our preliminary results indicate that the hydration program provided to coaches and athletes significantly improved their hydration knowledge [7]. Interestingly, there were larger and more significant improvement among athletes who have been playing for only 1-3 years compared to those who have been playing for $4-5$ years. We believe that athletes who have been playing for more than 3 years already have integrated their knowledge of proper hydration as they have been educated in their earlier playing years. However, we are still investigating if this knowledge is applied in actual scenario.

\section{References}

1. Binkley HM, Beckett J, Casa DJ, Kleiner DM, Plummer PE (2002) National Athletic Trainers' Association Position Statement: Exertional Heat Illnesses. J Athl Train 37: 329-343

2. Geijer J, Pitney W, Brandenburg J (2009) Fluid Replacement Knowledge and Sources of Hydration Information among Illinois High School Athletic Coaches. Internet Journal of Allied Health Science and Practice 7: 3

3. Rosenbloom CA, Jonnalagadda SS, Skinner R (2002) Nutrition knowledge of collegiate athletes in a Division I National Collegiate Athletic Association institution. J Am Diet Assoc 102: 418-420.

4. Jessri M, Jessri M, RashidKhani B, Zinn C (2010) Evaluation of Iranian college athletes' sport nutrition knowledge. Int J Sport Nutr Exerc Metab 20: 257-263.

5. Casa DJ, Armstrong LE, Hillman SK, Montain SJ, Reiff RV, et al. (2000) National athletic trainers' association position statement: fluid replacement for athletes. J Athl Train 35: 212-224

6. Maughan RJ, Shirreffs SM (2010) Development of hydration strategies to optimize performance for athletes in high-intensity sports and in sports with repeated intense efforts. Scand J Med Sci Sports 20 Suppl 2: 59-69.

7. Dizon JMR, Pineda KL, Felizardo MA, Caguicla JM, Ramos JM, et al. (2013) The Proposed Hydration Protocol For Ust Uaap Athletes.
*Corresponding author: Janine Margarita R. Dizon, Department of Rehabilitation, University of South Australia, Australia, E-mail: Janine.Dizon@unisa.edu.au

Received December 12, 2013; Accepted December 16, 2013; Published December 23, 2013

Citation: Dizon JMR (2013) Are Athletes Properly Hydrating: What do we Know? J Sports Med Doping Stud 4: e140. doi:10.4172/2161-0673.1000e140

Copyright: (c) 2013 Dizon JMR. This is an open-access article distributed under the terms of the Creative Commons Attribution License, which permits unrestricted use, distribution, and reproduction in any medium, provided the original author and source are credited. 